\title{
Usefulness of Polymerase Chain Reaction in the diagnosis of asymptomatic malaria among school age children in Ilorin, Nigeria
}

\author{
Ayodele Adedoja ${ }^{1^{*}, 2,3}$, Shola Kola Babatunde ${ }^{4}$, Bukola Deborah Tijani ${ }^{3}$, Ajibola A. Akanbi \\ II $^{5}$, Olusola Ojurongbe ${ }^{2}$ \\ ${ }^{1}$ Department of Biological Sciences, Achievers University, Owo, Nigeria \\ ${ }^{2}$ Department of Medical Microbiology and Parasitology, Ladoke Akintola University of Technology, \\ Osogbo, Nigeria, \\ ${ }^{3}$ Department of Medical Microbiology and Parasitology, University of Ilorin Teaching Hospital, Ilorin, \\ Nigeria, \\ ${ }^{4}$ Department of Biological Sciences Kings University, Odeomu, Nigeria \\ ${ }^{5}$ Department of Medical Microbiology and Parasitology, University of Ilorin, Ilorin, Nigeria
}

\begin{abstract}
*Correspondence should be addressed to Ayodele Adedoja: ayodeleadedoja@gmail.com
Received 21 December 2018; Revised 7 January 2019; Accepted 8 January 2019

(C) 2019 Adedoja et al. Licensee Pan African Journal of Life Sciences. This is an Open Access article distributed under the terms of the Creative commons Attribution License (https://creativecommons.org/licenses/BY/4.0), which permits unrestricted use, distribution, and reproduction in any medium, provided the original work is properly cited.
\end{abstract}

\begin{abstract}
Introduction: In Nigeria, microscopy and Rapid Diagnostic Tests (RDTs) are majorly used routinely to diagnose malaria in clinical settings. In recent years, molecular diagnosis has emerged as the most sensitive method for malaria diagnosis. This study determined the usefulness of Polymerase Chain Reaction (PCR) in comparison to microscopy (Giemsa stained thick and thin smears) for the diagnosis of asymptomatic malaria in Ilorin, Nigeria.
\end{abstract}

Methods: The study enrolled 310 school children aged 4-15 years with no sign or symptoms of malaria. Blood samples were collected for identification of Plasmodium species infection using light microscopy and conventional PCR.

Results: The PCR method detected more infection of P. falciparum 107 (34.5\%) than slide microscopy $81(26.1 \%)$ in the study. Only $P$. falciparum was detected by microscopy while PCR detected mono infection of $P$. malariae (3.2\%) and P. ovale (o.6\%) and mixed infection of $P$. falciparum and $P$. $m a-$ lariae (3.2\%). Overall the PCR method detected more malaria parasite compared to microscopy.

Conclusion: The PCR technique, although more laborious and expensive than microscopy, have better diagnostic accuracy and are highly useful for the detection of $P$. falciparum and other malaria species in asymptomatic and low parasitaemia cases.

Keywords: Malaria, Asymptomatic, diagnosis, PCR, Nigeria 


\section{1.o INTRODUCTION}

Despite remarkable achievements in reducing malaria mortality, malaria remains the most common cause of morbidity and mortality in sub-Saharan Africa [1,2]. It is a life threatening parasitic disease transmitted by infected female Anopheles mosquitoes and a major public health concern worldwide, causing 219 million infections and approximately $90 \%$ of the_malaria deaths the same year [3]. The disease is endemic in parts of Asia, Africa, Oceania, and Central and South America, with around $90 \%$ of the global malaria burden borne by Sub-Saharan Africa [3]. Malaria is endemic throughout Nigeria accounting for $25 \%$ of infant mortality and $30 \%$ of childhood mortality [4]. About 50\% of the population has at least one episode of malaria each year [4]. Nigeria has more reported cases of malaria and deaths due to malaria than any other country in the world [4].

Malaria presents a diagnostic challenge to laboratories in most countries [5]. In tropical countries, malaria may present clinical signs and symptoms like in other diseases thus making the diagnosis of malaria difficult especially in the resource poor regions. Signs and symptoms of malaria include intermittent fever, body aches and pains, malaise, generalized body weakness which may be presented by typhoid disease [5]. Prompt and accurate diagnosis of malaria is essential for effective disease management in any setting; delayed treatment increases the risk of death or serious neurological sequelae [6]. The early symptoms of malaria (fever, chills, headache, body aches, nausea, and vomiting) and physical findings (fever, pallor) are not specific and may be indicative of any number of diseases $[5,6]$. Common and life threatening infections such as viral and bacterial infections could present same signs and symptoms to malaria making clinical diagnosis quite challenging and unreliable [6]. The signs and symptoms of malaria and other tropical diseases overlap, and this may affect the diagnostic specificity and sensitivity, thereby increasing the wrong use of antimalarial and reduction in the effective management of patients with non-malarial febrile illness especially in the tropical Africa [6]. Therefore precise laboratory diagnosis is reqiured to achieve effective treatment of malaria.

There are several methods in the laboratory for the diagnosis of malaria parasites in the peripheral blood, including microscopy, antigen detection and polymerase chain reaction (PCR). Common tradition is to detect malaria by microscopic examination of blood smears for Plasmodium species. However, newer diagnostic methods are being used in both endemic and nonendemic areas to detect malaria parasitemia. Microscopy has historically been the mainstay of the diagnosis of malaria. The detection of asexual parasites by light microscopy of Giemsa-stained thick and thin films remains the standard laboratory method for the diagnosis of malaria $[7,8]$. Although easy to apply and cost-effective, this technique assumes that laboratories have certain infrastructure in place with highly skilled professionals and in detecting low level parasitaemia, so the sensitivity may fluctuate depending upon the skill of technician [9-12]. World Health Organization has recognized the urgent need for simple and cost-effective diagnostic tests for malaria to overcome the deficiencies of both light microscopy and clinical diagnosis [13]. To overcome such limitations, several methods have been in use. These include the staining of parasite DNA and RNA with acridine orange, the quantitative buffy coat method (QBC). Rapid Diagnostic Tests (RDTs) methods based on the detection of the enzyme lactate dehydrogenase (pLDH) and circulating $P$. falciparum histidine rich protein-2 (PfHRP-II) $[14,15]$ are now playing an important role in the prompt and accurate diagnosis of malaria.

Polymerase chain reaction (PCR) based assays have been used mainly for the assessment of the sensitivity and specificity of microscopy $[16,17]$. PCR based tests have shown remarkable capacity to detect malarial parasites in mixed infections and low parasite count and are also sensitive when compared to microscopic examination [18]. PCR can detect malaria infections with parasitemia as low as $0.01-0.2$ parasites/ $\mu \mathrm{L}$ of blood $[16,17]$. The value of PCR as a means of malaria parasite diagnostic technique lies in its sensitivity, its capability of identifying malaria parasites to the species level, as well as its ability to detect five parasites or less/ $\mu$ l of blood [17]. However, it is not appropriate for use in the field, as it is an expensive and complex method.

Many studies have revealed higher sensitivity of PCR in comparison to microscopy mostly for the diagnosis of complicated and uncomplicated $P$. falciparum infection with paucity of information in asymptomatic cases and specie differentiation. The main objective of this study therefore was to evaluate the usefulness of PCR method in the diagnosis of Plasmodium species in asymptomatic cases.

\subsection{METHODOLOGY}

\subsection{Study area and population}

The study was conducted in Patigia rural community in Kwara State, Nigeria. The town is inhabited by the Nupe people who also exhibit a linguistic reportoire of the Yoruba dialect. The inhabitants are farmers, acquatic sellers/fishers and traders. Pategi is located in Pategi 
Local Government Area in Kwara State.The town lies on LatitudeAverage annual rainfall is about 1270 , which falls almost entirely during the wet season. The community falls into stable malaria transmission zone where malaria is present throughout the year with a marked increase during the raining season which normally runs from April to September. The town stands on higher level and the soil can be described as well drained, moderately leached and with moderate humus content. 843'59.988"N and Longitude 545'0.00o"E[19]. Average daily temperature is $37^{\circ} \mathrm{C}$ with minimum mean temperature of $20^{\circ} \mathrm{C}$ and maximum mean temperature of $39^{\circ} \mathrm{C}$.

\subsection{Ethical statement.}

The study was a cross sectional study. Five primary schools were randomly selected for the study in the LGA capitals.Purposive sampling technique was used to select children for the specimen collection. Blood specimen was taken from 310 primary schools pupils of ages 4-15 years. Inclusion criteria for the study include consent from parent or guardian, no intake of antimalaria during the preceding four weeks and absence of malaria symptoms (vomitting, loss of apetite, fever etc). Sick children and parents who refused to give their consent to participate in the study were excluded.

\subsection{Sampling techniques}

The study was a cross sectional study. Five primary schools were randomly selected for the study in the LGA capitals.Purposive sampling technique was used to select children for the specimen collection. Blood specimen was taken from 310 primary schools pupils of ages 4-15 years. Inclusion criteria for the study include consent from parent or guardian, no intake of antimalaria during the preceding four weeks and absence of malaria symptoms (vomitting, loss of apetite, fever etc). Sick children and parents who refused to give their consent to participate in the study were excluded.

\subsection{Microscopy method}

Thick and thin films were preparedfrom blood collected into EDTA bottle and stained using 10\% Giemsa method for 30 minutes. The slides were examined under light microscope (100X oil-immersion objective) by 2 experienced microscopists. Parasitaemia was calculated per $200 \mathrm{WBC}$ assuming $8000 \mathrm{WBC} / \mu \mathrm{L}$ of blood [20,21]. The slides were reported only negative upon not detecting any parasites when 200 fields of the slides were examined.

\subsection{DNA extraction and molecular detection}

Blood samples collected were transported to the
Molecular Biology Laboratory of Ladoke Akintola Univeristy of Technology, Osogbo for PCR diagnosis. Genomic DNA was isolated using QIAgen DNA Mini Kit blood and tissue (QIAGEN,Germany) according to the manufacturers's instructions. The extracted DNA was stored at $-2 \mathrm{O}^{\circ} \mathrm{C}$ until used. Nested PCR assay were carried out as previously described elsewhere [12]. DNA samples were amplified by species-specific primer pairs (Table 1) designed to amplify small subunit ribosomal ribonucleic acid (ssRNA) genes of P. falciparum, P.vivax, P.malariae, and P.ovale using the PCR technique originally described by Snounou et al. [22]. In brief, both the primary and nested amplifications were carried out in a $20 \mu$ reaction volume containing $10 \mathrm{X}$ buffer, $2.5 \mathrm{mM} \mathrm{MgCl} 2,200 \mu \mathrm{M}$ dNTPs, 200nM primers, and $1 \mathrm{U}$ Taq DNA-polymerase with approximately 10ng of DNA template on a PTC-200 Thermal cycler (Prime, UK). The Plasmodium genusspecific amplification was followed by $P$. falciparum, $P$. vivax, $P$. malariae, and $P$. ovale species-specific PCR amplification.

Thermal cycling parameters for first round of amplification were: initial denaturation at $94^{\circ} \mathrm{C}$ for $5 \mathrm{~min}$, followed by 30 cycles of $95^{\circ} \mathrm{C}, 5^{\circ} \mathrm{C}$ at 30 seconds respectively and $72^{\circ} \mathrm{C}$ at $1: 20 \mathrm{~min}$,for annealing temperature. Thermal cycling parameters for second round of amplification were: initial denaturation at $95^{\circ} \mathrm{C}$ for $5 \mathrm{~min}$, followed by 40 cycles of $95^{\circ} \mathrm{C}, 58^{\circ} \mathrm{C}$, and $72^{\circ} \mathrm{Cfor} 45$ seconds for annealing temperature. In each run negative and positive controls were included.

Genomic DNA from healthy as well as from individuals who have not travelled to malaria-endemic areas were included as negative controls in all PCR diagnostic assays. Amplicons were separated on a 1.2\% agarose gel electrophoresis run along with a 100obp DNA ladder (Invitrongen, Karlsruhe, Germany). The presence or absence of different Plasmodium species was confirmed with representative amplicon size that were speciesspecific. Samples that failed to amplify were subjected to repeated amplification procedures with different PCR additives. Chances of cross contamination was strictly monitored and prevented following stringent quality control procedure.

\section{3.o RESULTS}

The enrollment data of the study group are summarized in Table 1. The mean age was 9.10 ( $\mathrm{SD} \pm 1.937)$ years. Polymerase chain reaction (PCR) detected more $P$. falciparum 107 (34.5\%) parasite than slide microscopy $81(26.1 \%)$. Only a single specie of $P$. falciparum was detected by microscopy while $P$. malariae (3.2\%) and $P$. ovale (0.6\%) and mixed infection of $P$. falciparum and $P$. malariae (3.2\%) were detected by PCR. 
Table 1: Enrollment data of the participants recruited in the study

\begin{tabular}{ll}
\hline Characterisic & Outcome \\
\hline Number of subjects examined & 310 \\
Mean age (years) \pm SD & $9.10 \pm 1.937$ \\
Sex (male/female) & $152 / 158$ \\
Number positive by microscopy (P. alciparum) & $81(26.1 \%)$ \\
Number of subjects positive by PCR & \\
P. falciparum & $105(33.8 \%)$ \\
P.malariae & $10(3.2 \%)$ \\
P.ovale & $(0.6 \%)$ \\
P. falciparum + P.malariae & $10(3.2 \%)$ \\
\hline
\end{tabular}

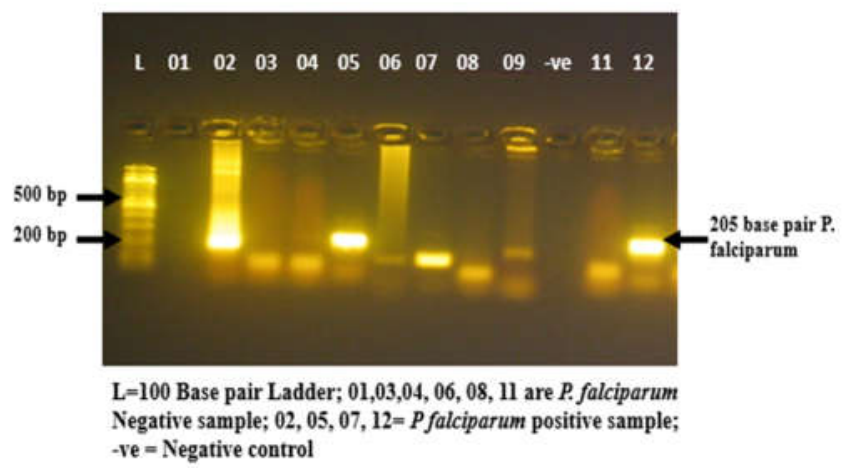

Figure 1: Agarose gel electrophoresis picture of $P$. falciparum PCR

The PCR and microscopy at different Plasmodium falciparum parasite densities is shown in Table 2. All smear positive for Plasmodium by microscopy were also positive by PCR at all parasitaemia levels. However, more infection were detected at density below 500 parasites/ $\mu \mathrm{L}$.

Table 2: PCR and microscopy at different Plasmodium falciparum parasite densities

\begin{tabular}{lll}
\hline $\begin{array}{l}\boldsymbol{P} \text {. falciparum } \\
\text { Parasites/ } \boldsymbol{\mu L}\end{array}$ & $\begin{array}{l}\text { No. Detected by } \\
\text { microscopy }\end{array}$ & $\begin{array}{l}\text { No. Positive by } \\
\text { PCR (\%) }\end{array}$ \\
\hline $1-<99$ & 20 & $20(100.0)$ \\
$100-249$ & 41 & $41(100.0)$ \\
$250-499$ & 10 & $10(100.0)$ \\
$500-999$ & 6 & $6(100.0)$ \\
$1000-4999$ & 4 & $4(100.0)$ \\
\hline
\end{tabular}

\section{4.o Discussion}

Microscopic examination of Giemsa-stained thick and thin blood smears has been the diagnostic method of choice for Plasmodium species identification in epidemiologic studies and medical diagnosis [21]. The method is simple, does not require highly equipped facilities, and in most cases enables differentiation among the four Plasmodium species causing malaria in human when performed by a trained medical laboratory technician. However, microscopy is often timeconsuming and laborious, and it is estimated that even a skilled person can evaluate only 60 to 80 specimens per day under field conditions [23,24]. This method can sometimes be misleading in identifying parasite species, especially in the case of low level of parasitemia and a mixed parasite infection [24] or modification by drug treatment. PCR based methods have been consistently shown to be powerful tool for malaria diagnosis [21]. Studies else where have shown that nested PCR, is more sensitive diagnostic method for malaria than microscopy, particularly in cases of low parasitemia and mixed infections [18]. The PCR analysis for Plasmodium species done in this study showed a sensitivity of $80.4 \%$. In the present study, slide microscopically failed to detect parasite in some positive samples, giving some false negative results. False negatives are a big public health problem because the patient would miss correct diagnosis and treatment, thus not complying with the rule "fast and correct diagnosis, and treatment with confirmed presence of the parasite" [25]. This could have grave implications in health, transmission, and possibly mortality. Accurate diagnostic methods are the basis for adequate disease control and avoiding resistance to antimalarial drugs or the spread of resistance.

In the present study, 12 cases (10 cases for $P$. malariae and 2 cases for $P$. ovale) which were not detected by microscopy were detected by PCR. This might be due to the presence of low level of parasitemia. Other studies have also reported the ability of PCR to detect low level of parasitemia undetected by conventional microscopy [2628]. Nested PCR could detect parasite DNA even in very low parasite count where microscopy could not detect, and PCR could also distinguish the species which was misdiagnosed by microscopy [16,17]. In practice, PCRbased assays may not replace microscopy for routine diagnosis in developing country Nigeria. However, nested PCR would be useful in discriminating the low parasitic infection cases strongly suspected by the clinicians but not supported by microscopy. Though it was observed that slide microscopically failed to detect parasite in many positive samples.

However PCR-positive results were obtained for same samples with coinfection of other species of Plasmodium detected which were not detected by microscopy. This observation is in line with other studies elsewhere [2932]. The low sensitivity by microscopy can be due to several factors. It could be as a result of suboptimal staining of the smear which may result into poor staining 
of the malaria parasites. Giemsa staining method is commonly employed by most clinical laboratories in the tropical countries to stain malaria smears. In Nigeria, the stain is readily available over the counter in most medical equipment stores and patent medicine stores with questionable quality. Even with the good quality stain and staining method, poor quality and inadequately maintained microscope could fail to detect parasites at low parasitaemia. An experienced person in a reference laboratory would not be expected to detect parasitaemia lower than 50 parasites/ $\mu$ l by microscopy [33].The microscopist who is not adequately trained and fatigued by high workload could miss out low parasite density. However, even when working under best conditions microscopy based malaria slide examination cannot detect the very low parasitaemia that PCR-based method can achieve. The PCR could detect a low sensitivity of 0.5 parasites $/ \mu l[31,32,34]$, which would practically be impossible for an experienced person achieve with light microscope. Furthermore, inability to detect low parasitaemia by microscopically may probably be as a result of submicroscopic malaria infections which might be related to the immunity status. The present study was among asymptomatic infected school age children. In malaria endemic countries, acquired immunity is associated with the submicroscopic infections that may not be seen under microscope easily by the clinical technician. Submicroscopic infections have been reported in high transmission regions in sub-Saharan African countries such as Ghana and Uganda among children $[35,36]$. Previous studies have shown that malaria parasite densities is associated with the stage of the infection [37,38], level of acquired immunity [25,39] and the genetic diversity of circulating parasite clones [40]. In addition to the argument that malaria parasiteamia can be influenced by immunity, there could be false PCR positivity as it can be explained by other mechanisms. PCR may remain positive for several week after systemic clearance of malaria from an effective drug treatment, as a result of residual asexual parasites and presence of gametocytaemia [26]. This may be eliminated by employing a mitochondrial PCR. This is sensitive in detecting gametocytes because gametocytes stage harbour up to eight mitochondria organelles, compared to the ring stage which harbours only one organelle [30]. Failure to observe good laboratory practices in a PCR laboratory can result in false positivity due to contamination. Contamination can occur in all steps of the procedure giving false amplification products [30].

In this study the sensitivity and specificity for PCR were $80.4 \%$ and $100.0 \%$, respectively. Other studies obtained in Nigeria had obtained different sensitivity and specificity. Ogbolu and others obtained a sensitivity and specificity of $29.4 \%$ and $100 \%$ in a study in Ile-Ife [27] in south western Nigeria, Kanyi and others $53.8 \%$ and 100\% in Lagos [28] and Waggoner et al. obtained 97.1\% and $93.5 \%$ also in Lagos [39]. It has been estimated that a diagnostic test with $95 \%$ sensitivity and $95 \%$ specificity requiring minimal infrastructure would avert more than 100,000 deaths and about 400 million unnecessary treatments [40].

Our results highlight the importance and usefulness of PCR in the diagnosis of asymptomatic malaria in among children. Although microscopy is cheap, readily assessible and can be used in field epidemiological study, however, PCR would give the correct prevalence of the running parasite in the community because the submicroscopic parasites would eventually be detected. For prevalence studies it is better to continue using microscopy as a reference technique and PCR to confirm negative results from microscopy.

\section{Conflict of interest}

The authors declare that there is no conflict of interest

\section{References}

1. WHO: World malaria report 2018. Geneva: World Health Organization.

2. Murray CJ, Rosenfeld LC, Lim SS, Andrews KG, Foreman KJ, Haring D, et al. Global malaria mortality between 1980 and 2010: a systematic analysis. Lancet. 2012;379:413-31.

3. Kolawole OM, Mokuolu OA, Olukosi YA, Oloyede TO. Comparative prevalence of Plasmodium falciparum malaria in patients attending Okelele Health Centre, Okelele, Ilorin, Nigeria. Indian J Health Sci Biomed Res 2017;10:57-62.

4. National Malaria Control Programme; 2013. Available from: http://www.afro.who.int/index.php option= com_docman\&task $=$ doc_download\&gid $=3340 \& I t e m i d=21$ 11. [accessed on 2018 Dec 12]

5. Indrani G, Sridevi K. Comparative Study Of Diagnosis Of Malaria By Smear Test, Quantitative Buffy Coat (QBC) Method And Rapid Kit Method. "IOSR Journal of Dental and Medical Sciences (IOSR-JDMS) 2018; 17 (4): 45-49.

6. Wogu MN, Nduka FO. Evaluating Malaria Prevalence Using Clinical Diagnosis Compared with Microscopy and Rapid Diagnostic Tests in a Tertiary Healthcare Facility in Rivers State, Nigeria. Journal of Tropical Medicine 2018; 3:1-4

7. Ameh J, Ahmad RM, Ekeh N, Linga P, Mangoro Z, Imam AU, Akeredolu P, Hudu S. Laboratory diagnosis of malaria: Comparing Giemsa stained thick blood films with rapid diagnostic test (RDT) in an endemic setting in North-west Nigeria. Journal of Medical Laboratory and Diagnosis 2012; 3(2): 10-15. 
8. Murray CK, Gasser RA, Magill AJ, Miller RS. Update on rapid diagnostic testing for malaria. Clin. Microbiol. Rev. 2008; 21:97-110.

9. Mayengue PI, Batsimba DK, Dossou-Yovo LR, Niama RF, Macosso L, Singana BP, Louzolo I, Loukabou NCB, Obili GS, Kobawila SC, Parra HP. Evaluation of Routine Microscopy Performance for Malaria Diagnosis at Three Different Health Centers in Brazzaville, Republic of Congo. Malaria Research and Treatment; 2018, Article ID 4914358, 6 pages https:// doi.org/10.1155/2018/4914358

10. Chinkhumba J, Skarbinski J, Chilima B, Campbell C, Ewing V, San Joaquin M, Ali D, Mathanga D: Comparative field performance and adherence to test results of fourmalaria rapid diagnostic tests among febrile patients more than five years of age inBlantyre, Malawi. Malar J 2010, 9:209.

11. Endeshaw T, Graves PM, Ayele B, Mosher AW, Gebre T, Ayalew F, Genet A, Mesfin A, Shargie EB, Tadesse Z, Teferi T, Melak B, Richards FO, Emerson PM: Performance of local light microscopy and the ParaScreen Pan/Pf rapid diagnostic test to detect malaria in health centers in Northwest Ethiopia. PLoS One 2012; 7:e33014.

12. Mekonnen SK, Aseffa A, Berhe N, Teklehaymanot T, Clouse RM, Gebru T, Medhin G,Velavan TP: Return of chloroquinesensitive Plasmodium falciparum parasites and emergence of chloroquine-resistant Plasmodium vivax in Ethiopia. $M a-$ lar $J$ 2014; 13:244.

13. World Health Organization, "Guidelines for the treatment of malaria,” 3rd edition, http://www.who.int/malaria/ publications/ atoz/9789241549127/en/, 2015.

14. World Health Organization. False-negative RDT results and implications of new reports of $P$. falciparum histidine-rich protein 2/3 gene deletions. Geneva: WHO 2016.

15. Harchut K, Standley C, Dobson A, Klaassen B, RambaudAlthaus C, Althaus F, et al. Over-diagnosis of malaria by microscopy in the Kilombero Valley, Southern Tanzania: an evaluation of the utility and cost-effectiveness of rapid diagnostic tests. Malar J. 2013; 12:159

16. Cordray MS, Richards-Kortum RR. Emerging nucleic acidbased tests forpoint-of-care detection of malaria. Am J Trop Med Hyg. 2012; 87:223-30.

17. Mosha JF, Sturrock HJ, Greenhouse B, Greenwood B, Sutherland CJ,Gadalla N, et al. Epidemiology of subpatent Plasmodium falciparum infection:implications for detection of hotspots with imperfect diagnostics. Malar J. 2013; 12:221

18. Mahende C, Ngasala B, Lusingu J, Yong T, Lushino P, Lemnge M, Mmbando B, Premji Z. Performance of rapid diagnostic test, blood $\square$ film microscopy and PCR for the diagnosis of malaria infection among febrile children from Korogwe District, Tanzania. Malar J 2016; 15:391 DOI 10.1186/s12936-016-1450-z

19. Adedoja A, Tijani BD, Akanbi AA II, Ojurongbe TA, Adeyeba OA, Ojurongbe O Coendemicity of Plasmodium falciparum and Intestinal Helminths Infection in School Age Children in Rural Communities of Kwara State Nigeria. PLoS Negl TropDis, 2015; 9(7): doi:10.1371/journal. pntd.ooo3940.
20. Moody A., Rapid Diagnostic Tests for Malaria Parasites, Rev Clin Microbiol; 2002, 15:166-78

21. Rantala A, Taylor SM, Trottman PA, Luntamo M, Mbewe B, Maleta K,Kulmala T, Ashorn P, Meshnick SR.Comparison of real-time PCR and microscopy for malaria parasite detection in Malawian pregnant women. Malaria Journal 2010, 9:269

22. Snounou GS, Viriyakosol S, Zhu P, Jarra W, Pinheiro L, do Rosario VE, Thaithong S, Brown KN. High sensitivity of detection of human malaria parasites by the use of nested polymerase chain reaction. Mol. Biochem. Parasitol. 1993; 61:315-320.

23. Okell LC, Bousema T, Griffin JT, Ouedraogo AL, Ghani AC, Drakeley CJ. Factors determining the occurrence of submicroscopic malaria infections and their relevance for control. Nat Commun. 2012;3:1237.

24. Ngasala B, Mubi M, Warsame M, Petzold MG, Massele AY, Gustafsson LL, et al. Impact of training in clinical and microscopy diagnosis of childhood malaria on antimalarial drug prescription and health outcome at primary health care level in Tanzania: a randomized controlled trial. Malar Journal.2008;7:199.

25. Mosha JF, Sturrock HJ, Greenhouse B, et al. Epidemiology of subpatent Plasmodium falciparum infection: implications for detection of hotspots with imperfect diagnostics. Malar Journal 2013; 12:221

26. Bousema T, Okell L, Felger I, Drakeley C. Asymptomatic malaria infections: detectability, transmissibility and public health relevance. Nature reviews Microbiology. 2014; 12 (12):833-40. doi: 10.1038/ nrmicro3364 PMID: 25329408.

27. Ogbolu DO, Alli OAT, Nassar AS, Ajagbe OO. Evaluation of usefulness of polymerase chain reaction in the diagnosis of malaria in Nigeria. African Journal of Clinical and Experimental Microbiology. 2012; 13(3) doi:10.4314/ajcem.v13i3.1

28. Kanyi OI, Ajayi MB, Ezeugwu SMC, Afocha EE, Iwalokun.Comparison Of Rapid Diagnostic Test (Rdt), Polymerase Chain Reaction (Pcr) And Microscopy Methods In The Diagnosis Of Malaria Among Airport Workers In Lagos. Nigerian Journal of Science and Environment, 2016: 13 (1) 1824

29. Ncogo P, Herrador Z, Romay-Barja M, García-Carrasco E, Nseng G, Berzosa P, et al. Malaria prevalence in Bata district, Equatorial Guinea: a crosssectional study. Malar Journal. 2015;14:45.

30. Haanshuus CG, Chandy S, Manoharan A, Vivek R, Mathai D, Xena D, et al. (2016) A High Malaria Prevalence Identified by PCR among Patients with Acute Undifferentiated Fever in India. PLoS ONE 11(7): e0158816. doi:10.1371/journal. pone.0158816

31. Krishna S, Bharti PK, Chandel HS, Ahmad A, Kumar R, Singh PP, et al. Detection of Mixed Infections with Plasmodium spp. by PCR, India, 2014. Emerg Infect Dis. 2015; 21 (10):1853-7. doi: 10.3201/ eid2110.150678

32. Gupta B, Gupta P, Sharma A, Singh V, Dash AP, Das A. High proportion of mixed-species Plasmodium infections in India revealed by PCR diagnostic assay. Trop Med Int Health. 
2010; 15(7):819-24. doi: 10. 1111/j.1365-3156.2010.02549.x

33. Murphy SC, Shott JP, Parikh S, Etter P, Prescott WR, Stewart VA. Malaria diagnostics in clinical trials. Am J Trop Med Hyg. 2013; 89(5):824-39. doi: 10.4269/ajtmh.12-0675

34. Van Hong N, van den Eede P, Van Overmeir C, Vythilingham I, Rosanas-Urgell A, Vinh Thanh P, et al. A modified seminested multiplex malaria PCR (SnM-PCR) for the identification of the five human Plasmodium species occurring in Southeast Asia. Am J Trop Med Hyg. 2013; 89(4):721-3. doi: 10.4269/ ajtmh.13-0027 PMID: 23980132

35. Roh ME, Oyet C, Orikiriza P, Wade M, Kiwanuka GN, Mwanga-Amumpaire J, et al. Asymptomatic Plasmodium infections in children in low malaria transmission setting, Southwestern Uganda. Emerg Infect Dis.2016;22:1494-8.

36. Arwati H, Yotopranoto S, Ainum Rohmah E, Syafruddin D. Sub-microscopic malaria cases play role in local transmission in Trenggalek district, EastJava Province, Indonesia. Malar Journal. 2018;17:2.

37. Mogeni P, Williams, TN. Omedo I, Kimani D, Ngoi JM, Mwacharo J, Morter R,Nyundo C, Wambua J, Nyangweso G, Kapulu M, Fegan G, Bejon P, Detecting Malaria Hotspots: A Comparison of Rapid Diagnostic Test, Microscopy, and Poly- merase Chain Reaction. The Journal of Infectious Diseases. 2017;216:1091-8.

38. Okell LC, Bousema T, Griffin JT, Ouédraogo AL, Ghani AC, Drakeley CJ. Factors determining the occurrence of submicroscopic malaria infections and their relevance for control. Nat Commun 2012; 3:1237.

39. Shittu O, Opeyemi OA, Ajibaye O, Omotesho BO, Fakayode O. Evaluation of the Clinical Proficiency of RDTs, Microscopy and Nested PCR in the Diagnosis of Symptomatic Malaria in Ilorin, North-Central, Nigeria. Open Access Maced J Med Sci. 2018 Jun 20; 6(6):1032-1040. https://doi.org/10.3889/ oamjms.2018.218

40. Waggoner JJ, Okangba C, Mohamed-Hadley A, Lefterova MI, Banaei N, Oyibo W, Pinsky BA. Molecular Testing for Plasmodium falciparum using Serum or Plasma and Comparison with Microscopy and Rapid Diagnostic Testing in Febrile Nigerian Patients. J. Clin. Microbiol. 2015. doi:10.1128/JCM.01876-15. http://jcm.asm.org/ assessed on December 19, 2018. 